Karen Adiel D. Rances, MD'

Emmanuel Tadeus S. Cruz, MD',2

Arsenio L. Pascual, MD'

Jomar S. Tinaza, MD'

'Department of Otorhinolaryngology

Head \& Neck Surgery

Quezon City General Hospital and Medical Center

${ }^{2}$ Department of Otorhinolaryngology

Head \& Neck Surgery

Manila Central University-Filemon D. Tanchoco

Medical Foundation
Correspondence: Dr. Arsenio L. Pascual

Department of Otorhinolaryngology-Head \& Neck Surgery

Quezon City General Hospital and Medical Center

Seminary Road, Munoz, Quezon City 1106

Philippines

Phone: (632) 4261314 local 232

Fax: (632) $9207081 ; 9206270$

Email: orl_hns_qcgh@yahoo.com.ph

Reprints will not be available from the author

The authors declared that this represents original material that is not being considered for publication or has not been published or accepted for publication elsewhere in full or in part, in print or electronic media; that the manuscript has been read and approved by the authors, that the requirements for authorship have been met by the authors, and that the authors believe that the manuscript represents honest work.

Disclosures: The authors signed disclosures that there are no financial or other (including personal) relationships, intellectual passion, political or religious beliefs, and institutional affiliations that might lead to a conflict of interest.

Presented at Philippine Society of Otolaryngology Head and Neck Surgery Descriptive Research Contest, September 19, 2013. Natrapharm, The Patriot Bldg., KM 18 SLEX, Paranaque City.

\title{
A Case Series of Tessier 3, 4, 7 and Combined 4, 7 Craniofacial Clefts
}

ABSTRACT

Objective: To report a case series of Tessier 3, 4, 7 and combined 4,7 craniofacial clefts, their clinical presentations, surgical approaches and outcomes in light of the current literature.

\section{Methods:}

$\begin{array}{ll}\text { Design: } & \text { Case series } \\ \text { Setting: } & \text { Tertiary Government Hospital } \\ \text { Subjects: } & \text { Five patients }\end{array}$

Results: Five patients aged 3 to 14-years-old with Tessier 3, 4 (2 cases), 7 and combined 4,7 were included in this study: Tessier 3 - medial orbitomaxillary cleft extending through the bony skeleton traversing obliquely across the lacrimal groove, Tessier 4 - median orbitomaxillary cleft traversing vertically through the inferior eyelid, infraorbital rim and orbital floor extending to the lip between the philtral crest and the oral commissure (2 cases), Tessier 7 - macrostomia and cleft oral commissure and combined Tessier 4 and 7, combining features described above. Four underwent 2- or 3-stage surgeries while one declined.

Conclusion: Five craniofacial clefts were presented. Because of the varying patterns of craniofacial deformities, a series of surgical procedures, tailor-made for each individual were performed on four. Otolaryngologists who perform maxillofacial and cosmetic surgery should have good background knowledge about craniofacial defects and be familiar with the surgical approaches at their disposal to yield favorable results that are appropriate to their local contexts.

Keywords: Tessier Clefts No. 3, 4 and 7, oculoplasty, commisuroplasty, alar transpositional flap, canthopexy

Craniofacial clefts are among the rare congenital malformations with an incidence of between 1.43 to 4.85 per 100,000 births. ${ }^{1}$ To our knowledge, less than 50 cases of Tessier No. 4 clefts have been reported. 'The Tessier Classification System is a craniofacial cleft nomenclature devised by Paul Tessier in 1976 wherein he assigned a specific number to the site of each malformation based on its relationship to the sagittal midline of the facial bone. ${ }^{2}$

Aside from genetic factors, environmental factors and the interplay of the two may contribute to the development of facial clefts. ${ }^{3}$ Although new cases of craniofacial clefts are encountered locally, few are documented in the literature. For instance, we only found two local articles on facial clefts by Tian et al. ${ }^{4}$ and Chiong et al. ${ }^{5}$ in this journal. Because of improvements in perinatal and pediatric care, there is a good possibility that more affected individuals will seek reconstructive surgery.

We present five such cases, their clinical presentations, surgical approaches and outcomes.

Philipp J Otolaryngol Head Neck Surg 2015; 30 (1):34-38

(c) Philippine Society of Otolaryngology - Head and Neck Surgery, Inc. 
ORIGINAL ARTICLES

Philippine Journal Of Otolaryngology-Head And Neck Surgery

Vol. 30 No. 1 JANUARY - JUNE 2015

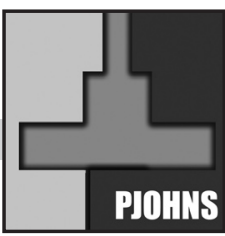

\section{CASE REPORTS}

\section{Case 1}

A 3-year- old boy with a Tessier 4 cleft had the following deformities: inferior eyelid coloboma on the right eye, bilateral cleft along the lateral margin of the cupids bow, epicanthal fold and microphthalmia on the left and cleft palate. (Figure 1A) He had undergone facial repair with an interdigitating local flap 3 years ago and palatoplasty the following year. Present examination revealed inferior eyelid coloboma of the right eye, epicanthal fold and microphthalmia on the left. (Figure 1B) Because of the redundant skin flap over the right inferior orbital rim from the previous surgery, revision was performed using transposition of upper-lid pedicle flap. (Figure 2) After two weeks, the flap was resected horizontally at the midline to facilitate eye opening.

\section{Case 2}

A 3-year-old boy with Tessier 4 cleft underwent cheiloplasty in 2010 and palatoplasty in 2011. The patient had a bilateral lower eyelid coloboma and corneal exposure. A simultatneous revision palatoplasty for oronasal fistula and oculoplasty via bilateral canthopexy were performed. (No consent was given to reproduce his photos).

\section{Case 3}

A 14-year-old boy with a Tessier 3 cleft presented with bilateral lower eyelid coloboma, distortion of the frontal process of the maxilla on the right, coloboma of the nasal ala and midline cleft lip with absence of philtrum. The cleft passed across the lacrimal segment through the soft tissue vertically extending to the alar base. (Figure 3)

Transposition of eyelid pedicle flap and medial canthopexy were done on both eyes. For the naso-malar component, soft tissue dissection and alar transposition advancement flap was done. The cleft lip was repaired with a straight-line closure. CT scan two days after surgery revealed hypoplasia of naso-maxillary bone and alveolar process. (Figure 4) A structural rhinoplasty and scar revision will be performed in the future.

\section{Case 4}

A 4-year-old boy with a Tessier 7 cleft presented with unilateral minor macrostomia (cleft length of 1-2 cm), left oral commissure cleft and preauricular skin tag. Left lateral oral commisuroplasty was done and the preauricular skin tag was excised. (Figure 5)

\section{Case 5}

A 5-year-old girl with combined Tessier 4 and 7 unilateral clefts on the left presented with an orbitomaxillary cleft that traversed the inferior eyelid and infraorbital rim extending onto the lip between the philtral

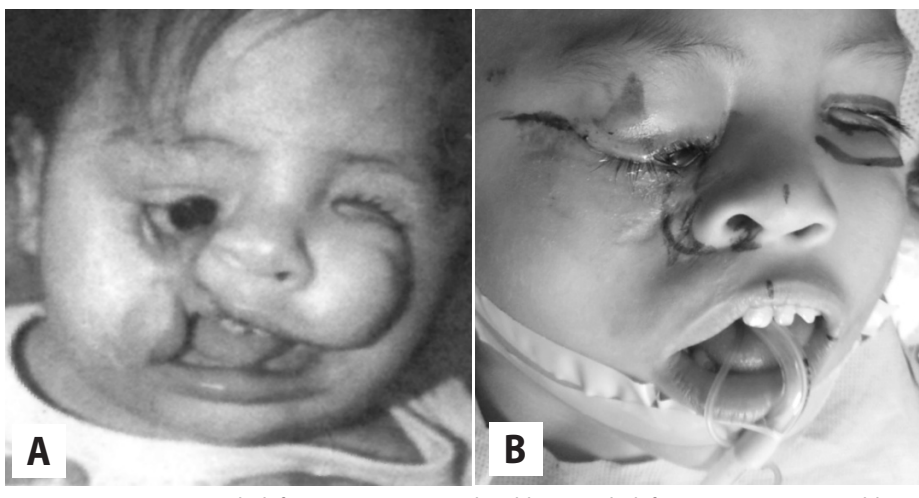

Figure 1. Case 1. A. Facial Cleft Tessier 4 at 6-months-old B. Facial Cleft Tessier 4 at 3-years-old, s/p facial repair with an interdigitating local flap and palatoplasty. Present examination revealed inferior eyelid coloboma of the right eye, epicanthal fold and microphthalmia on the left. Photos printed in full with permission.
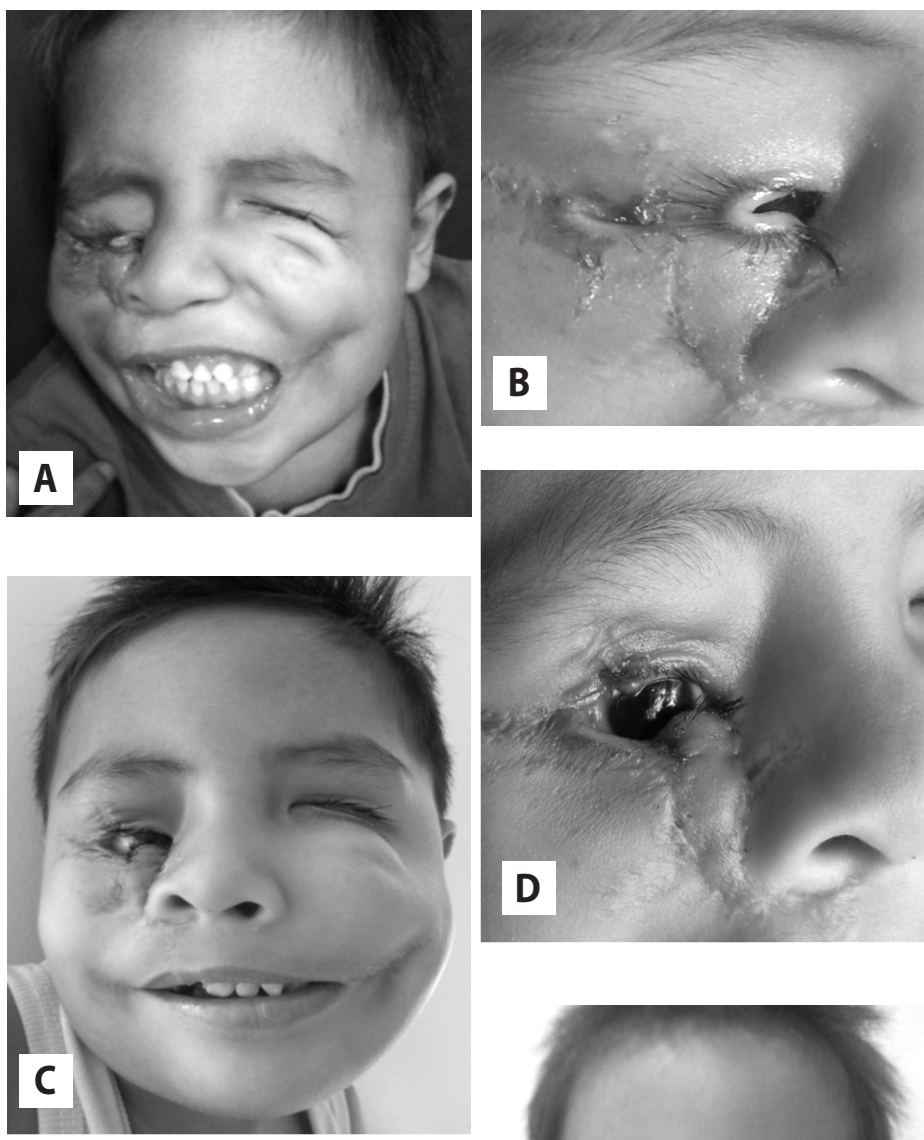

Figure 2. A \& B. Note the redundant skin flap ove the right inferior orbital rim from the previous surgery C \& D. Revision reconstruction using pedicled upper eyelid flap after a week; resected eyelid flap. E. Resected eyelid flap after 3 months. Photos printed in full with permission.
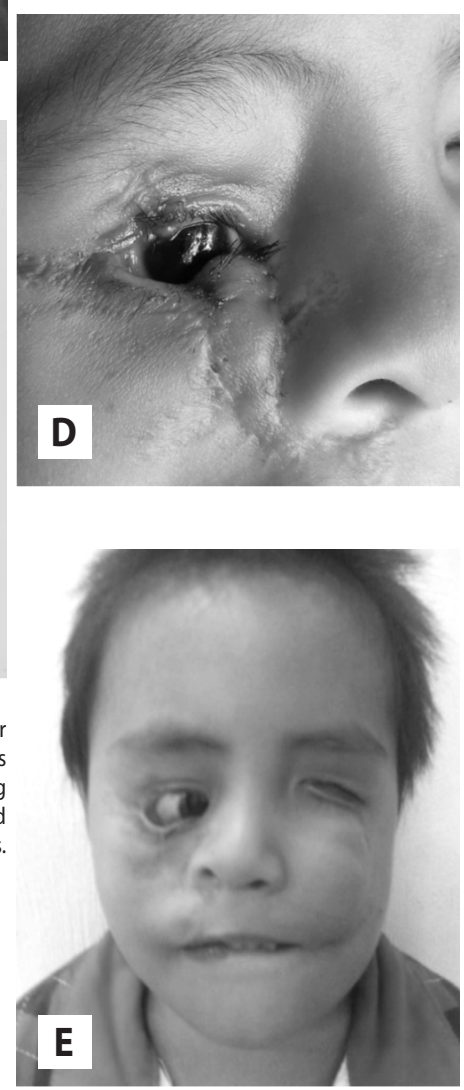

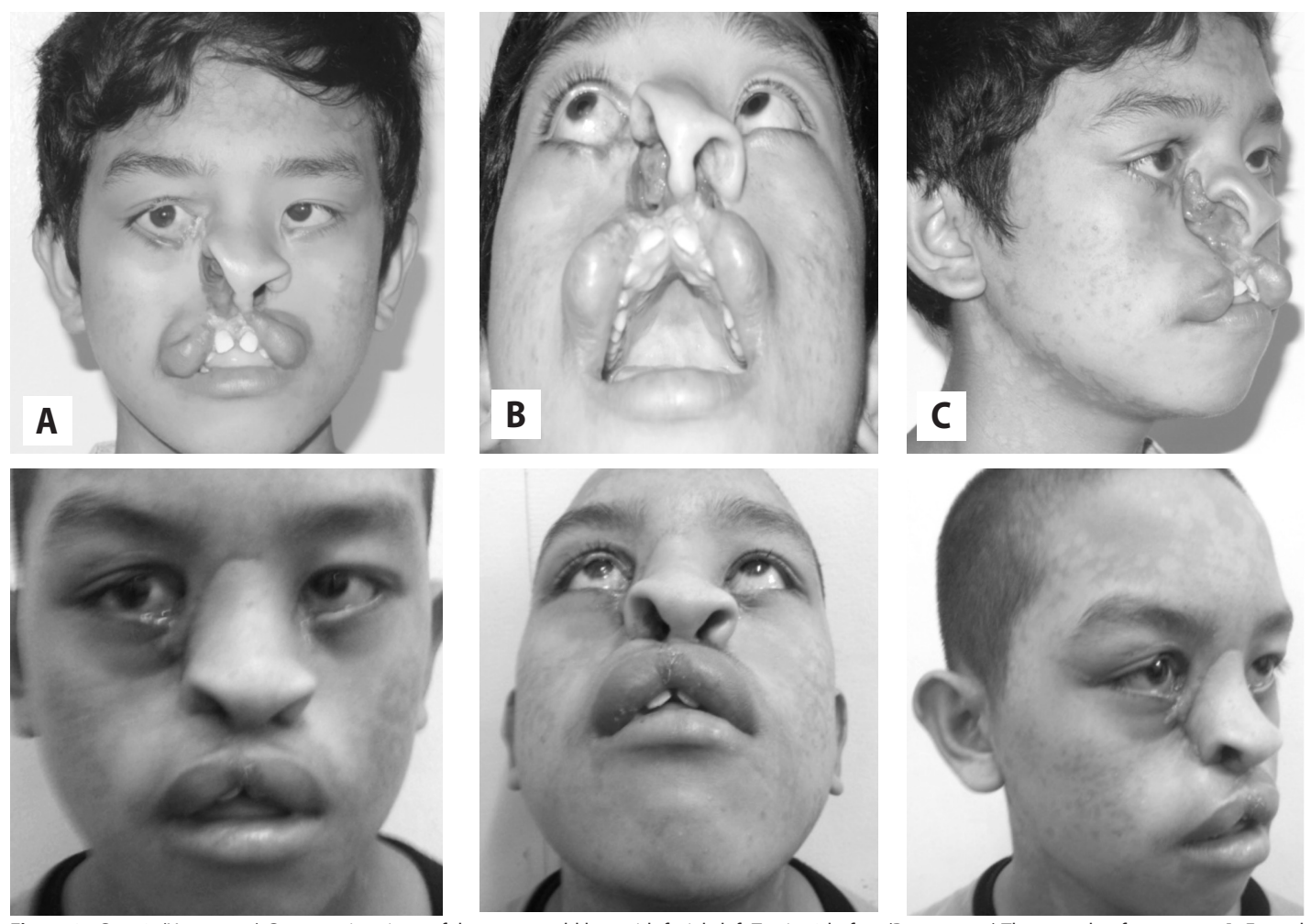

Figure 3. Case 3. (Upper row) Comparative views of the 14-year-old boy with facial cleft Tessier 3 before (Bottom row) Three weeks after surgery A. Frontal views B. Antero-inferior views C. Right lateral views of orofacial deformity. Photos printed in full with permission.
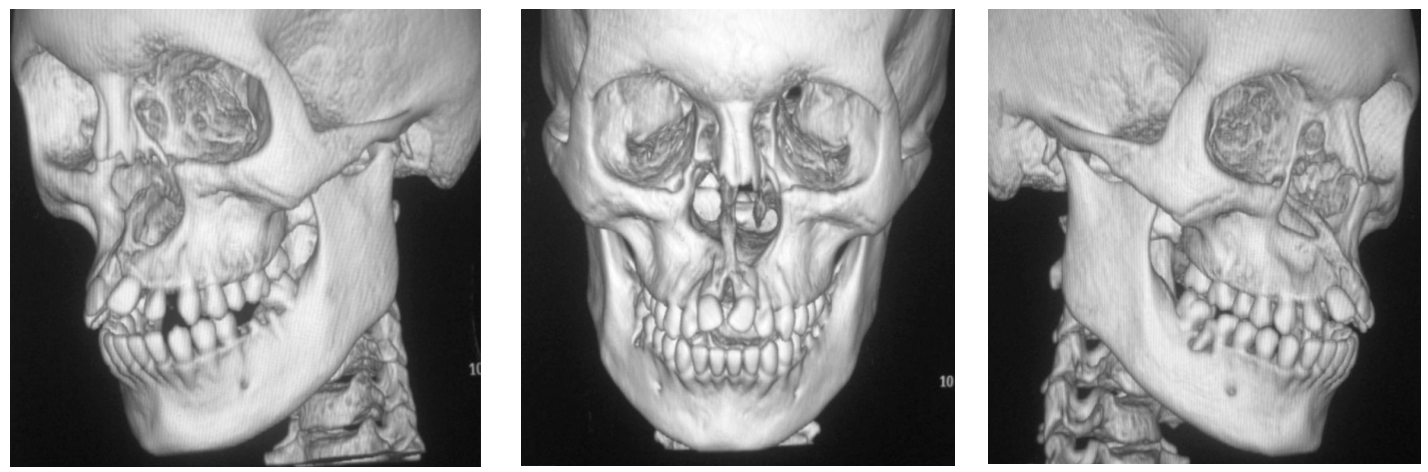

Figure 4. Three-dimensional Reconstruction CT scan of the Tessier 3 patient. Note hypoplasia of naso-maxillary bone and alveolar process and cleft between the upper central incisors.
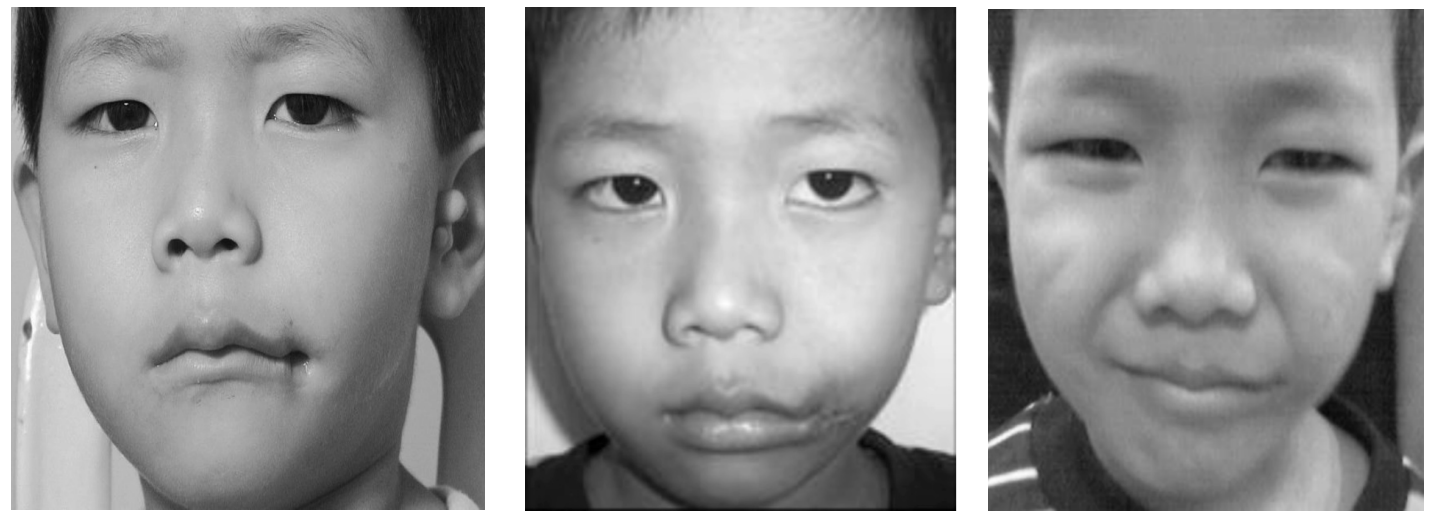

Figure 5. Case 4: The boy with Tessier 7 cleft. Left, macrostomia, commissure cleft and preauricular skin tag;(Center) After commisuroplasty; (Right) Two weeks after the surgery. Photos printed in full with permission. 
ORIGINAL ARTICLES

crest and the oral commisure. She also had ipsilateral macrostomia and a cleft oral commissure. (Figure 6) Unfortunately, her family refused surgery.

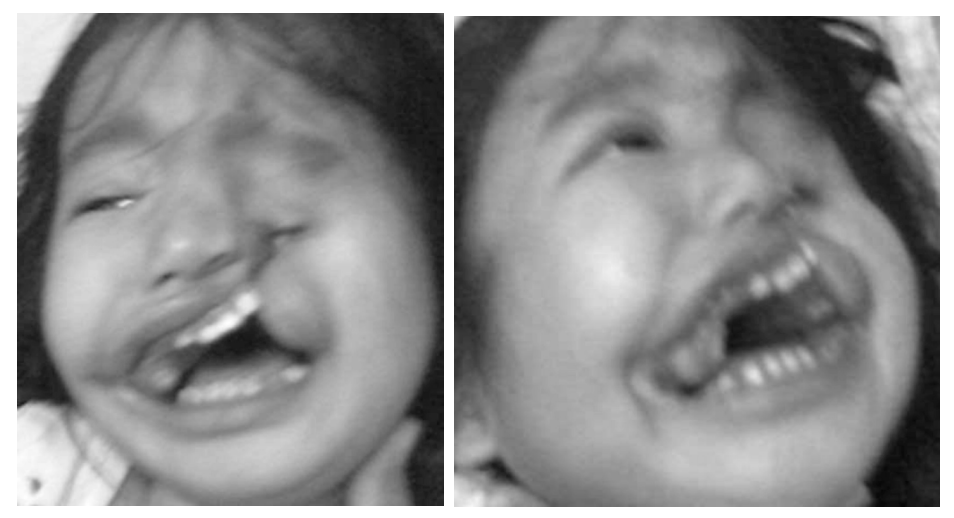

Figure 6. Case 5: A 5-year-old female with combined Tessier 4 \& 7 cleft. The parents refused surgery Photos printed in full with permission

\section{DISCUSSION}

Facial clefts may be defined as a gap (hypoplasia), misshapen face (dysplasia), interruption or deficiency in the continuity of a soft tissue (coloboma) or fissure in the soft tissue, bone or a combination of both. It may be located in the forehead, eyes, cheeks, mouth, nostrils and lips. ${ }^{6}$

Craniofacial defects may be diagnosed or classified under the Tessier Classification. This is the most widely used system which schematically assigns and designates numbers to describe craniofacial clefts. ${ }^{2}$ Based on this classification, the patients in this study include a Tessier 3 cleft - medial orbitomaxillary cleft that extends through the bony skeleton as a paranasal cleft traversing obliquely across the lacrimal groove with often complete absence of the anterior and medial wall of the maxillary sinus; two Tessier 4 clefts - medial orbitomaxillary cleft traversing vertically through the inferior eyelid, infraorbital rim extending to the lip between the philtrum crest and the oral commissure; a Tessier 7 (lateral or transverse cleft) - macrostomia and cleft oral commisure and presence of preauricular skin tag; and a combined Tessier 4 and 7 cleft, with features as described above. Four cases underwent 2- or 3-stage surgeries while one case declined. In a recent study, Butow proposed a new classification of lateral facial clefts based on the direction of the anatomical appearance as follows: T7.1 superiorly rotated, T7.2 - middle positioned, T7.3 inferiorly rotated and T7.4, agenetic type. ${ }^{7}$

A for embryology, a Tessier 3 cleft results from failure of closure of the naso-optic groove between the frontonasal and medial maxillary processes; a Tessier 4 cleft has been ascribed to primary arrest of development, neurovascular insufficiency or a result of tears in the developing maxillary process; while a Tessier 7 cleft may result from incomplete fusion of the mesodermal merging of the maxillary and mandibular processes. ${ }^{3}$
The etiology of orofacial clefts is multifactorial. Environmental factors include exposure to radiation and chemicals, intake of teratogenic drugs (retinoic acid, phenytoin, valproic acid and corticosteroid), maternal cigarette smoking, and folate deficiency during pregnancy. ${ }^{3}$ Genetic factors also play a role in the development of facial clefts.

Other than embryologic abnormalities in the fusion of frontonasal and maxillary processes, the size of the facial processes affects facial morphology and susceptibility to develop a cleft. A smaller median nasal process or midface among Asians and flat nasal structures may predispose to orofacial cleft development while the reverse is true for Africans with broad, larger noses and increased facial widths representing well developed median nasal processes and a decreased propensity for clefting. ${ }^{3}$ A comprehensive discussion on the incidence, etiology, inheritance, transmission risks of orofacial clefting by Eppley is available in the literature. ${ }^{3}$

Case 1 (Tessier No. 4) was previously repaired with interdigitating local flaps but the result was not satisfactory due to scarring. Case 2 (Tessier No. 4) had bilateral lower eyelid colobomas and corneal exposure. Some surgeons would consider a Mustarde cheek rotational flap to reconstruct such large defects of the cheek as the upper flap edge will provide tissue for the lower eyelid. ${ }^{1}$ Other have utilized z-plasty, advancement flap of the cheek and tissue expansion methods to close the defect. ${ }^{8}$ We employed an upper-lid pedicle flap for the first case and bilateral canthopexy to reduce corneal exposure on our second case. (Figures 2, 3)

Features of a Tessier 3 cleft include inferior displacement of medial canthus, superior displacement of the alar base, cleft lip and palate, coloboma of the lower eyelid, nasolacrimal abnormality, disruption of medial wall of antrum, cleft of inferomedial wall of the orbit and telorbitism. ${ }^{9}$ Anophthalmia or microphthalmia may be a feature of Tessier 3 clefts. ${ }^{9}$ Our third case had bilateral lower eyelid coloboma, distortion of the frontal process of the maxilla on the right, coloboma of the nasal ala and midline cleft lip with absence of philtrum.

Cizmezi ${ }^{8}$ performed an alar transposition flap and irregular z plasty in a patient with Tessier 3 cleft. Because of the severe facial disfigurement, the patient had dropped out from school due to low self-esteem and isolation from his peers. After a series of surgeries, his cosmetically acceptable appearance provided renewed self-confidence and hope for a brighter future. In our case, transposition of eyelid pedicle flap and medial canthopexy were done on both eyes and soft tissue dissection and alar transposition advancement flap were employed for the nasomalar component. The cleft lip was repaired with a straight-line closure. A structural rhinoplasty and scar revision will be performed in the future. (Figure 5) 
Mishra and Purwar proposed formatting a 'split approach' for the surgical management of Tessier 3 and 4 clefts in which the affected areas of the cleft were divided into three: lid, lip and nasomalar components. The formatting is done to segregate the cleft into different compartments. Afterwards, the surgical blueprint is drawn and performed one after the other. They concluded that formatting provides technical ease with pleasing surgical results after doing surgery in seven cases of Tessier 3 and $4 .{ }^{10}$

The Tessier 7 cleft is the most common among orofacial clefts with an incidence of 1 in 3000 neonates and is often associated with multiple congenital syndromes. It rarely occurs bilaterally (10-20\% of cases). ${ }^{11}$ It has been described as craniofacial macrostomia, first and second branchial arch syndrome and otomandibular dysostosis. ${ }^{12}$

Table 1. Summary of the clinical features and surgery of the 5 patients

\begin{tabular}{|c|c|c|c|c|}
\hline Case & $\begin{array}{l}\text { Age/ } \\
\text { Sex }\end{array}$ & Tessier & Features & Management \\
\hline 1 & $3 / \mathrm{M}$ & 4 & $\begin{array}{l}\text { lower eyelid coloboma, } \\
\text { right epicanthal fold; } \\
\text { bilateral cleft through the } \\
\text { lateral margin of the cupids } \\
\text { bow; microphthalmia, left; } \\
\text { cleft lip and palate }\end{array}$ & $\begin{array}{l}\text { Cheiloplasty with } \\
\text { facial repair using } \\
\text { interdigitating local flap, } \\
\text {, uranoplasty; upper lid } \\
\text { pedicle flap }\end{array}$ \\
\hline 2 & $3 / M$ & 4 & $\begin{array}{l}\text { Lower eyelid coloboma, } \\
\text { bilateral; corneal exposure; } \\
\text { cleft lip and palate }\end{array}$ & $\begin{array}{l}\text { Cheiloplasty; } \\
\text { uranoplasty; canthopexy }\end{array}$ \\
\hline 3 & $14 / M$ & 3 & $\begin{array}{l}\text { bilateral lower eyelid } \\
\text { coloboma, distortion of } \\
\text { frontal process of maxilla } \\
\text { on the right, coloboma } \\
\text { of the nasal ala, midline } \\
\text { cleft lip with absence } \\
\text { of philtrum; the cleft } \\
\text { passes across the lacrimal } \\
\text { segment through the soft } \\
\text { tissue vertically extending } \\
\text { to the alar base. }\end{array}$ & $\begin{array}{l}\text { Transposition of eyelid } \\
\text { pedicle flap and medial } \\
\text { canthopexy, straight } \\
\text { line closure technique; } \\
\text { soft tissue dissection } \\
\text { and alar transposition } \\
\text { advancement flap }\end{array}$ \\
\hline 4 & $4 / M$ & 7 & $\begin{array}{l}\text { Unilateral macrostomia, left } \\
\text { oral commissure cleft and } \\
\text { preauricular skin tag. }\end{array}$ & $\begin{array}{l}\text { Lateral commisuroplasty } \\
\text { via straight-line closure } \\
\text { None }\end{array}$ \\
\hline 5 & $5 / \mathrm{F}$ & 4,7 & $\begin{array}{l}\text { orbitomaxillary cleft } \\
\text { that traverses vertically } \\
\text { involving the inferior eyelid, } \\
\text { infraorbital rim extending } \\
\text { onto the lip between the } \\
\text { philtrum crest and the oral } \\
\text { commisure, macrostomia } \\
\text { and cleft oral commisure }\end{array}$ & \\
\hline
\end{tabular}

Gokrem reported five cases of Tessier 7 lateral facial clefts on the left or right oral commissure managed with the Skoog technique that utilizes z-plasty in the skin closure. ${ }^{12} \mathrm{~A}$ commisureplasty was performed in our patient.

We presented five cases of craniofacial clefts. Because of the varying patterns of craniofacial deformities, a series of surgical procedures was tailor-made for each individual. Soft tissue reconstruction was the common denominator used in the surgical techniques of the four cases operated on while others would integrate bone, cartilage grafts or implants in the reconstruction of such defects. (Table 1)

Orofacial clefts involve the skin, subcutaneous tissue, muscle and mucosa and do not necessarily extend to the bony structures. To document bony involvement, CT scan evaluation is required. Among our five cases, only the patient with a Tessier 3 cleft had a post-operative CT scan that revealed hypoplasia of the right nasomaxillary and upper alveolar process hypoplasia. A limitation of this series is that none of the patients were preoperatively evaluated for bony involvement. Whether such evaluation should be routine in low-income settings such as ours where costs outweigh benefits is arguable.

Surgical management of orofacial clefts is complicated, challenging and requires experience, expertise and craft. Otolaryngologists who perform maxillofacial and cosmetic surgery should have good background knowledge in dealing with these deformities and be familiar with the conventional and contemporary diagnostic and surgical approaches to yield favorable results that are appropriate to their local contexts.

\section{ACKNOWLEDGEMENTS}

The authors would like to thank Dr. Peter Ayliffe who performed surgery on two patients (Cases 1 and 3) and for his inputs in the course of preparing the manuscript, and Dr. Lhea Descartin for the photographs of the three patients (Cases 1, 2 and 3).

\section{REFERENCES}

1. Coruh A, Gunay GK. A surgical conundrum: Tessier number 4 cleft. Cleft Palate Craniofac J. 2005 Jan; 42(1): 102-106.

2. Greenberg AM, Prein J. Craniofacial Reconstructive and Corrective Bone Surgery: Principles of Internal Fixation using the AO/ASIF technique. New York: Springer, 2002. pp 23-37.

3. Eppley BL, van Aalst, JA, Robey A, Havlik RJ, Sadove AM. The spectrum of orofacial clefting. Plast Reconstr Surg. 2005 Jan; 115(7): 101-113.

4. Tian PG, Chua AH, Nolasco FP. Clefts beyond the lip and palate: A case series on facial clefts. Philipp J Otolaryngol Head Neck Surg. 1999 Jan-Mar; 14(1): 28-33.

5. Chiong AT, Guevarra ES, Zantua RV. Oblique Facial Cleft. Philipp J Otolaryngol Head Neck Surg 1982; 88-93.

6. Smith PB. Tessier Clefts. American Cleft Palate Foundation. [cited 2003 Jan]. Available from: www. cleftline.org/docs/tessierinfo.pdf

7. Butow KW, Botha A. A classification and construction of congenital lateral facial clefts. $J$ Craniomaxillofac Surg. 2010 Oct; 38(7): 477-84.

8. Cizmeci, O, Kuvat SV. Tessier No. 3 incomplete cleft reconstruction with alar transposition and irregular Z-plasty. Plast Surg Int. 2011; 2011: 596569.

9. Wenbin Z, Hanjiang W, Xiaoli C, Zhonglin L. Tessier 3 cleft with clinical anophthalmia: two case reports and a review of literature. $2007 \mathrm{Jan} ;$ 44(1): 102-105.

10. Mishra RK, Purwar R. Formatting the surgical management of Tessier cleft 3 and 4. Indian J Plast Surg. 2009 Oct; 42 Suppl: S174-83.

11. Shires CB, Hodges JM, Thompson J, Gorman M, Stocks R. Tessier 7: A case report and literature review. Laryngoscope. 2009; 119: 148.

12. Gokrem S, Ozdemir OM, Katircioglu A, Sen Z, Ersoy A, Can Z., et. al. A rare craniofacial cleft: Tessier No. 7: A retrospective Analysis. J Ankara Med Sch. 2002 Oct; 24(2): 63-68. 